\title{
Update on the Management of Helicobacter pylori Infection
}

\section{Nasir Saleem Colin W. Howden ${ }^{*}$}

\author{
Address \\ *Division of Gastroenterology, University of Tennessee College of Medicine, 956 \\ Court Avenue, Suite H210, Memphis, TN, 38163, USA \\ Email: chowden@uthsc.edu
}

Published online: 17 July 2020

C Springer Science+Business Media, LLC, part of Springer Nature 2020

Keywords $H$. pylori · Antibiotics - Antibiotic resistance • Clarithromycin · Rifabutin • Vonoprazan

\begin{abstract}
Purpose of review Our purpose was to provide an update on methods and indications for testing and treatment selection focusing on novel modalities.

Recent findings Increasing antibiotic resistance has reduced treatment effectiveness. Antibiotic resistance testing is not widely available in North America where there are insufficient resistance and susceptibility data. Quadruple regimens (bismuth-based or concomitant/non-bismuth-based) have been recommended first-line. A rifabutin-based combination product recently approved by the US Food and Drug Administration is highly effective and should simplify treatment. The potassium-competitive acid blocker vonoprazan is being evaluated as part of dual or triple combination regimens. Molecular-based genotypic testing for antibiotic resistance and an effective $H$. pylori vaccine remain under development.

Summary Inability to test for antibiotic resistance renders treatment selection empiric. However, resistance to rifabutin and amoxicillin remains rare. Effective management continues to comprise appropriate diagnostic testing for active infection, utilization of an effective regimen, and post-treatment testing.
\end{abstract}

\section{Introduction}

Helicobacter pylori (H. pylori) infection is one of the most common chronic bacterial infections in humans affecting approximately 4.4 billion people worldwide, with a prevalence of 28 to $84 \%$ in different populations $[1,2]$. The incidence and prevalence of $H$. pylori infection are higher among people born outside North America compared with those among people born here. However, the prevalence is high within certain communities in North America and varies with socioeconomic status and race/ethnicity [3-6]. In general, the prevalence is lower among non-Hispanic whites compared with other groups such as African Americans, Hispanics, Native Americans, Alaska Natives, and Americans of Korean or Chinese ancestry $[7,8]$.

H. pylori infection is implicated in the pathogenesis of gastritis, gastric and duodenal ulcers, gastric cancer, and gastric mucosa-associated lymphoid tissue (MALT) lymphoma [9-12]; its eradication is recommended in the treatment and/or prevention of these conditions [13, 14]. Treatment has also been 
recommended for patients with uninvestigated dyspepsia in the absence of alarm features, and for those with functional dyspepsia. Importantly, all patients with a positive test of active infection should be offered treatment $[3,15,16]$. However, $H$. pylori treatment has been complicated and has required 10 or 14 days of multiple daily doses of three or four different medicines. Furthermore, the effectiveness of many regimens has declined due to increasing antibiotic resistance [17-21] making $H$. pylori eradication challenging. The World Health Organization has included $H$. pylori among 12 bacterial species requiring high priority future strategies for new antibiotic development-due mainly to high rates of clarithromycin resistance $[22 \bullet \bullet]$. To address this global challenge, treatment guidelines for the management of $H$. pylori infection have been issued by expert groups in the USA [3], Canada [9], and Europe [12•]. However, the scarcity of data on antibiotic resistance among $H$. pylori strains from North America remains a major area of unmet clinical need prompting calls for concerted efforts to establish surveillance registries for resistance patterns and success rates to guide effective treatment [23]. Similarly, antimicrobial sensitivity testing for $H$. pylori performed on gastric biopsy specimens is not routinely available in most North American medical centers and requires upper gastrointestinal endoscopy; molecular methods to identify genetic mutations responsible for antibiotic resistance are not currently approved $[3,24]$. In this review, we discuss the important role of $H$. pylori in gastric cancer, the management of $H$. pylori infection with a focus on diagnostic testing including culture and sensitivity, molecular techniques for resistance testing, and novel therapies that are currently in development or that have recently been approved.

\section{H. pylori infection-a potentially modifiable risk fac- tor for gastric cancer}

$H$. pylori is an established gastric carcinogen, accounting for up to $89 \%$ of non-cardia gastric cancers globally [25]. In 2018, H. pylori was responsible for an estimated 810,000 new cases of non-cardia gastric adenocarcinoma worldwide, making it the leading cause of infection-attributable cancer ahead of high-risk human papillomavirus and hepatitis B and $C$ viruses [26]. The American Cancer Society has estimated that there will be 27,600 new cases of gastric cancer in the USA in 2020, and 11,010 attributable deaths $[27 \bullet \bullet]$. Of note, the burden of gastric adenocarcinoma in the USA exceeds that of

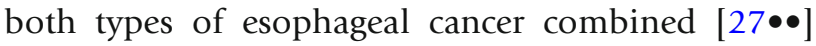
(Fig. 1). Importantly, evidence is accumulating that eradication of $H$. pylori infection in asymptomatic individuals reduces the risk of gastric cancer.

A retrospective study of 371,813 US veterans with H. pylori infection found a significantly reduced risk of gastric cancer among those with confirmed eradi-

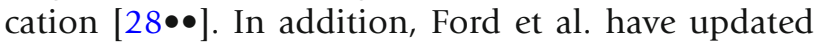
their previous systematic review and meta-analysis of randomized trials that examined the effect of $H$. pylori eradication therapy in asymptomatic individuals and the risk of gastric cancer $[14 \bullet \bullet]$. They included six studies that were performed in East Asian countries and one from South America. They found moderate evidence of the benefit of $H$. pylori eradication therapy in reducing both gastric cancer incidence and mortality; these were reduced by $46 \%$ and $39 \%$, respectively. They also confirmed the previously noted benefit of H. pylori eradication among patients who had endoscopic resection of early gastric neoplasia; treatment reduced the risk of further gastric cancer by $51 \%$

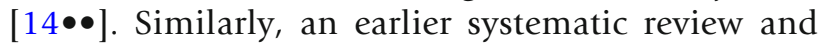
meta-analysis of six randomized trials and eight cohort studies by Lee et al. found that eradication of H. pylori reduces the risk of gastric cancer and may be the most viable strategy for primary gastric cancer prevention in asymptomatic infected individuals [29]. A randomized, placebo-controlled trial by Choi et al. in South Korea has shown that H. pylori eradication also reduces the risk of gastric cancer among persons who had a first-degree relative with gastric cancer $[30 \bullet \bullet]$.

\section{H. pylori testing}

In countries with high gastric cancer rates such as Japan, Korea, China, and Taiwan, population-based H. pylori screening has either begun or is under consideration [10, 31-33]. In North America, where the prevalence is lower than in Asia $[1,2]$, there is no current justification for population-based screening. However, there are certain established indications for $H$. pylori testing followed by treatment including active peptic ulcer disease (PUD), a past history of PUD (if cure of infection has not been documented), gastric intestinal metaplasia that is detected incidentally at endoscopy, gastric MALT lymphoma, history of endoscopic resection of early gastric cancer, and in patients with uninvestigated or functional 


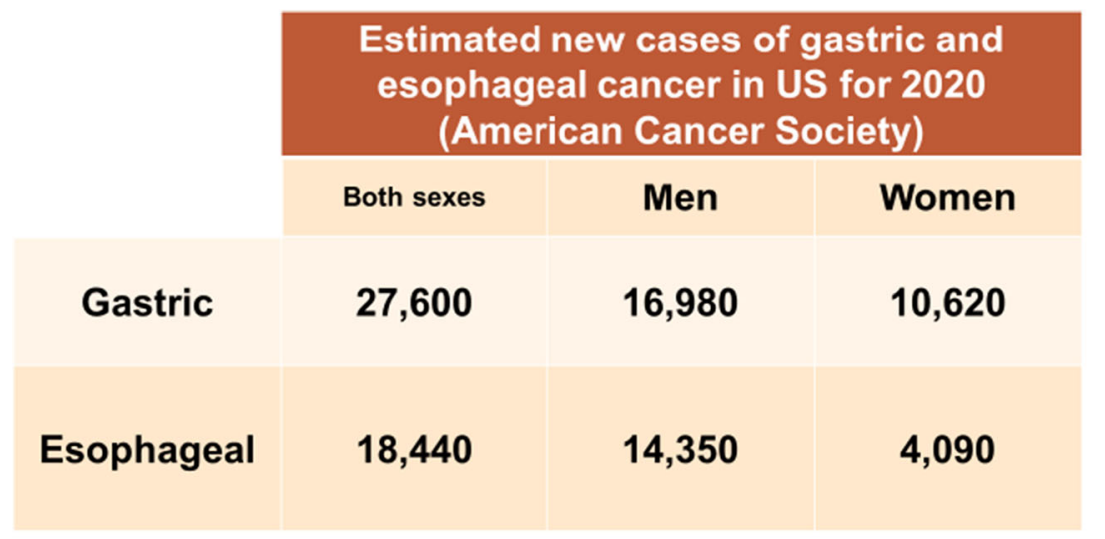

Adapted from Slegel et al, [Ref 27]

Fig. 1. The burden of gastric adenocarcinoma in the USA.

dyspepsia [3, 15, 34]. There is also evidence linking $H$. pylori to unexplained iron deficiency anemia, idiopathic thrombocytopenic purpura, and vitamin $\mathrm{B}_{12}$ deficiency. In these conditions, $H$. pylori infection should be sought and eradicated after other appropriate evaluation is done $[12,35]$.

$H$. pylori can be detected non-invasively with serology, the urea breath test (UBT) or the fecal antigen test. Although serological testing is widely available, it is no longer recommended due to its low positive predictive value among low prevalence populations, such as the USA. Furthermore, serological tests may remain positive after successful eradication $[12,36]$. However, according to the 2017 American College of Gastroenterology (ACG) guideline on $\mathrm{H}$. pylori treatment, it is acceptable to use serological testing in patients with a documented history of PUD (assuming that they have not already been treated for the infection). In most other circumstances, tests that identify active infection are preferred [ $3 \bullet$. Despite such recommendations, prior studies found that serology was the most commonly used $H$. pylori test in the USA $[37,38]$. However, the UBT and fecal antigen test are more highly sensitive and specific, detect only active infection, and are approved for both initial diagnosis and confirmation of eradication post-treatment $[3,31]$. If endoscopy is indicated, gastric biopsies can be collected pre- or post-treatment to determine H. pylori status by histology and/or biopsy-based urease testing. All tests to confirm eradication should be performed after discontinuing proton pump inhibitors (PPI) for at least 2 weeks and antibiotics and bismuthcontaining compounds for 4 weeks in order to avoid falsenegative results. Histamine $\mathrm{H}_{2}$-receptor antagonists or antacids can be used without affecting the accuracy of the UBT or fecal antigen test [31].
Invasive methods for $H$. pylori testing rely on endoscopy to obtain biopsies for urease activity, histopathology, or culture. Due to topographic variation in the density of $H$. pylori in the stomach, it is important to obtain biopsies from both the gastric body and antrum [39] - particularly when endoscopy has to be performed on a patient who was recently taking PPI treatment. Biopsy urease tests are widely used as they are simple, cheap, easy to perform, and accurate for patients who are not on a PPI. However, they are subject to inter-observer bias, can give equivocal results, and should be interpreted in the context of pretest probability and prevalence of $H$. pylori infection in the population $[36,40]$. The sensitivity of ureasebased testing may also be reduced by the presence of blood in the stomach [41]. Histopathological testing for $H$. pylori provides an additional assessment of the gastric mucosa, such as the presence of chronic active gastritis (presence of mucosal inflammation, particularly polymorphonuclear leukocytes) or gastric atrophy, intestinal metaplasia, or dysplasia. The sensitivity of histology for $H$. pylori detection can be improved by immunohistochemistry, especially when chronic active gastritis, a condition that is almost pathognomonic of $H$. pylori infection, is seen but no bacteria are immediately apparent [42]. The culture of gastric biopsy specimens has a specificity of $100 \%$ and allows for antimicrobial resistance testing. However, H. pylori culture requires stringent transport conditions, takes several days, and can be difficult to perform even in experienced hands. Its success is further complicated by the recent use of PPIs or antibiotics. Unfortunately, therefore, such testing is not widely available in the USA [3, 42]. 


\section{Culture and sensitivity testing-lack of local resis- tance and susceptibility data}

In contrast to the usual treatment of a bacterial infection, where choice of antimicrobial is guided by the organism's in vitro susceptibility and/or by local resistance data, treatment of $H$. pylori infection is still largely empiric. With increasing treatment failures, difficulty in eradicating $H$. pylori, and some evidence suggesting that culture-guided therapy is associated with higher eradication rates $[43,44]$, experts have called for more widespread antibiotic resistance testing. The Maastricht guidelines recommend clarithromycin resistance testing in regions where resistance is high before prescribing clarithromycin triple therapy or after the failure of second-line treatment $[12,31]$. Antibiotic susceptibility testing can be done by culture or molecular determination of genotype resistance, both of which require gastric biopsies-a major factor in precluding widespread adoption of this strategy. Performing endoscopy for the sole purpose of obtaining biopsies also makes this approach less cost-effective. Despite these issues, some experts advocate moving antibiotic susceptibility testing to an earlier phase than waiting for two treatment failures, mostly due to rising levofloxacin resistance, a component of many second-line regimens [23].

Although treatment guidelines strongly recommend using local susceptibility and resistance patterns for selecting $H$. pylori therapy, such data are lacking in many parts of the world [23]. The scarcity of such data in the USA was an impediment to making strong evidencebased treatment recommendations in the 2017 ACG guideline on $H$. pylori treatment [3•]. In the USA, only two publications over the last 20 years including fewer than 500 strains of $H$. pylori have described resistance characteristics [45, 46]. In Europe, a registry is recording real-time data on $\mathrm{H}$. pylori resistance patterns; this could be used to tailor future treatment recommendations [47]. There have been calls for similar registries to be set up across North America to provide local susceptibility data in an effort to improve eradication rates by recommending evidence-based first-line and salvage regimens $[23,31]$. This would entail universal availability of stool or gastric biopsy culture and susceptibility testing or molecular genotypic analysis.

\section{Molecular testing for $\boldsymbol{H}$. pylori}

Like other infectious agents, $H$. pylori can acquire resistance to various antibiotics. Therefore, susceptibility testing should be an important tool for effective treatment. $H$. pylori acquires resistance through genotypic mutation
[42]. The traditional phenotypic methods of culture and susceptibility testing can be applied to H. pylori. However, molecular methods such as polymerase chain reaction or fluorescence in situ hybridization to identify point mutations responsible for resistance, offer simpler and faster methods of detecting resistance and tailoring treatment accordingly. Molecular testing can detect resistance to clarithromycin and levofloxacin caused by point mutations but is not suitable for identifying metronidazole resistance that can be due to multiple mechanisms [24, 42]. Molecular tests can be performed on gastric biopsies obtained at endoscopy. Pre-treatment stool-based molecular testing, which obviates the need for endoscopy, should allow for a more universal transition from empiric to resistance-guided therapy but requires further development. While $H$. pylori strains are almost always sensitive to amoxicillin, tetracycline, and rifabutin, regimens containing clarithromycin or fluoroquinolones are increasingly ineffective for many populations because of increasing resistance rates [17, 23]. Individual susceptibility testing before first-line therapy is an attractive therapeutic approach but would require the widespread availability of molecular testing in stool samples. Currently, however, validated molecular testing on gastric biopsies or stool samples is not widely available and such tests remain under development [48, 49].

\section{Treatment with a focus on primary and salvage therapies}

All treatment guidelines agree that the best approach to the treatment of $H$. pylori infection is to succeed on the first attempt, thereby avoiding re-treatment and reducing cost, anxiety, and the further promotion of resistant strains [23]. As antibiotic susceptibility data are not usually available, empiric first-line therapies should be based on some knowledge of patients' previous antibiotic exposure and history of penicillin allergy, and on some understanding of local resistance rates. Bismuth-based quadruple therapy (BQT), concomitant/non-bismuth quadruple therapy, and clarithromycin-based triple therapy were recommended first-line options in the 2017 ACG guideline (Table 1) [3•]. However, clarithromycin-based triple therapy should only be used for patients who have had no previous exposure to macrolides and who come from regions where the local clarithromycin resistance rate is known to be under $15 \%$. This substantially limits the applicability of clarithromycin-based triple therapy. The ACG guideline also suggested non-bismuth sequential and non-bismuth hybrid quadruple therapies as first-line regimens, with the 
Table 1. American College of Gastroenterology recommended first-line therapies for Helicobacter pylori infection. Adopted from Chey et al. [3]

\begin{tabular}{|c|c|c|c|c|}
\hline Regimen & Drugs (doses) & $\begin{array}{l}\text { Dosing } \\
\text { frequency }\end{array}$ & $\begin{array}{l}\text { Duration } \\
\text { (days) }\end{array}$ & $\begin{array}{l}\text { FDA } \\
\text { approval }\end{array}$ \\
\hline $\begin{array}{l}\text { Clarithromycin } \\
\text { triple }\end{array}$ & $\begin{array}{l}\text { PPI (standard or double dose) Clarithromycin } \\
\quad(500 \mathrm{mg}) \\
\text { Amoxicillin }(1 \mathrm{~g}) \text { or Metronidazole (500 mg TID) }\end{array}$ & BID & 14 & $Y_{e s}^{a}$ \\
\hline $\begin{array}{l}\text { Bismuth } \\
\text { quadruple }\end{array}$ & $\begin{array}{l}\text { PPI (standard dose) } \\
\text { Bismuth subcitrate }(120-300 \mathrm{mg}) \text { or subsalicylate } \\
(300 \mathrm{mg}) \\
\text { Tetracycline }(500 \mathrm{mg}) \\
\text { Metronidazole }(250-500 \mathrm{mg})\end{array}$ & $\begin{array}{l}\text { BID } \\
\text { QID } \\
\text { QID } \\
\text { QID (250) } \\
\text { TID to QID (500) }\end{array}$ & $10-14$ & $\mathrm{No}^{\mathrm{b}}$ \\
\hline Concomitant & $\begin{array}{l}\text { PPI (standard dose) } \\
\text { Clarithromycin }(500 \mathrm{mg}) \\
\text { Amoxicillin }(1 \mathrm{~g}) \\
\text { Nitroimidazole }(500 \mathrm{mg})^{\mathrm{c}}\end{array}$ & BID & $10-14$ & No \\
\hline Sequential & $\begin{array}{l}\text { PPI (standard dose) + amoxicillin }(1 \mathrm{~g}) \\
\text { PPI, clarithromycin }(500 \mathrm{mg})+\text { nitroimidazole } \\
(500 \mathrm{mg})^{\mathrm{c}}\end{array}$ & $\begin{array}{l}\text { BID } \\
\text { BID }\end{array}$ & $\begin{array}{l}5-7 \\
5-7\end{array}$ & No \\
\hline Hybrid & $\begin{array}{l}\text { PPI (standard dose) + amoxicillin }(1 \mathrm{~g}) \\
\text { PPI, amoxicillin, clarithromycin }(500 \mathrm{mg}) \text {, } \\
\text { nitroimidazole }(500 \mathrm{mg})^{c}\end{array}$ & $\begin{array}{l}\text { BID } \\
\text { BID }\end{array}$ & $\begin{array}{l}7 \\
7\end{array}$ & No \\
\hline $\begin{array}{l}\text { Levofloxacin } \\
\text { triple }\end{array}$ & $\begin{array}{l}\text { PPI (standard dose) } \\
\text { Levofloxacin }(500 \mathrm{mg}) \\
\text { Amoxicillin }(1 \mathrm{~g})\end{array}$ & $\begin{array}{l}\text { BID } \\
\text { QD } \\
\text { BID }\end{array}$ & $10-14$ & No \\
\hline $\begin{array}{l}\text { Levofloxacin } \\
\text { sequential }\end{array}$ & $\begin{array}{l}\text { PPI (standard or double dose) + amoxicillin }(1 \mathrm{~g}) \\
\text { PPI, amoxicillin, levofloxacin (500 mg QD), } \\
\text { nitroimidazole }(500 \mathrm{mg})^{c}\end{array}$ & $\begin{array}{l}\text { BID } \\
\text { BID }\end{array}$ & $\begin{array}{l}5-7 \\
5-7\end{array}$ & No \\
\hline LOAD & $\begin{array}{l}\text { Levofloxacin }(250 \mathrm{mg}) \\
\text { PPI (double dose) } \\
\text { Nitazoxanide }(500 \mathrm{mg}) \\
\text { Doxycycline }(100 \mathrm{mg})\end{array}$ & $\begin{array}{l}\text { QD } \\
\text { QD } \\
\text { BID } \\
\text { QD }\end{array}$ & $7-10$ & No \\
\hline \multicolumn{5}{|c|}{$\begin{array}{l}\text { BID, twice daily; FDA, Food and Drug Administration; PPI, proton pump inhibitor; TID, three times daily; QD, once daily; QID, four times daily } \\
\text { a'Several PPI, clarithromycin, and amoxicillin combinations have achieved FDA approval. PPI, clarithromycin and metronidazole is not an FDA- } \\
\text { approved treatment regimen } \\
\text { bPPI, bismuth, tetracycline, and metronidazole prescribed separately is not an FDA-approved treatment regimen. However, Pylera, a combina- } \\
\text { tion product containing bismuth subcitrate, tetracycline, and metronidazole combined with a PPI for } 10 \text { days is an FDA-approved treatment } \\
\text { regimen } \\
\text { 'Metronidazole or tinidazole }\end{array}$} \\
\hline
\end{tabular}

caveats that their complexity could lead to poor patient compliance and low clinician preference, and that these had not been validated within North America. In the USA, BQT is probably the best empiric choice. Its efficacy is unrelated to possible clarithromycin resistance and-since it does not contain amoxicillin-there are no concerns about possible penicillin allergy. In a recent retrospective study from Rhode Island, it had an eradication rate of $87 \%[50 \bullet]$-as long as it included tetracycline; eradication rates were lower among patients who received doxycycline in place of tetracycline. An interim analysis of data from the European Registry on $H$. pylori management found that the addition of bismuth to 14-day standard clarithromycin-based triple therapy achieved eradication in more than $90 \%$ of patients [51 $\bullet$. This may be an alternative first-line therapy in regions with moderate clarithromycin resistance but where there are no susceptibility data available. Bismuth has a synergistic effect with 
several antibiotics that is independent of clarithromycin and metronidazole resistance.

In patients who fail first-line treatment, BQT or levofloxacin-based triple therapy are second-line options that avoid the re-use of clarithromycin; levofloxacin-based triple therapy should only be used second-line if levofloxacin was not used first-line. However, amoxicillin and tetracycline can be re-used due to continuing low resistance to these agents. Metronidazole, which has a synergistic effect with bismuth, can also be re-used [23] assuming patients can tolerate it.

Perceived allergy to penicillins (including amoxicillin) may be an obstacle to effective treatment of $H$. pylori infection. While up to $20 \%$ of the general adult population may consider themselves to be "allergic" to penicillin, over $90 \%$ can safely receive amoxicillin after appropriate negative skin testing [52•]. Therefore, the 2017 ACG guideline recommended allergy testing in patients who had failed first-line therapy and who reported a history of penicillin allergy.

After more than one failed attempt at eradication, the selection of a salvage regimen is required. The Maastricht guidelines recommend culture with susceptibility testing after the failure of second-line treatment. When such testing is not available, BQT or-if a fluoroquinolone had not been used initially-a levofloxacin-based regimen may be attempted. Both high-dose dual therapy (amoxicillin and PPI) and rifabutin-based regimens [53, 54] have been considered by all major guidelines but with variation in the strength of their recommendations (Table 2) [3, 9, 12, 23].

\section{Recent developments in $\boldsymbol{H}$. pylori treatment}

In the absence of access to reliable antimicrobial sensitivity testing and based on the above considerations, BQT is a reliable empiric choice for the treatment of H. pylori infection. Similarly, a study from China showed that BQT was as effective as targeted therapy based on sensitivity testing [55]. A systematic review and metaanalysis by Yang et al. showed that both BQT and highdose dual therapy achieve similar eradication rates and adherence, with the latter causing fewer side effects [56]. Other areas of development stem from promising results with high-dose dual regimens and rifabutin-based regimens.

The rationale for dual therapy with high doses of a PPI and amoxicillin is that $H$. pylori is only very rarely resistant to amoxicillin whose bactericidal effect on $H$. pylori increases at high gastric $\mathrm{pH}$ [57]. Treatment with high-dose PPI and at least $3 \mathrm{~g}$ /day of amoxicillin for 14 days has produced eradication rates of $70-89 \%$ in patients with one or more prior treatment failures [3, 58].

Another development is the 2019 approval by the United States Food and Drug Administration (FDA) of a combination product (Talicia ${ }^{\circledR}$; RedHill Biopharma, Raleigh, NC) containing omeprazole, rifabutin, and amoxicillin [59•]. This is the first and only FDA-approved rifabutin-based $H$. pylori therapy. Potentially, it may improve patient compliance with treatment because of its relative simplicity. In the "ERADICATE Hp2" trial, this combination successfully eradicated $H$. pylori in $84 \%$ of patients compared to $58 \%$ who received the same doses of omeprazole and amoxicillin, but without rifabutin. The recommended dose for this product is four capsules taken three times daily for 14 days; total daily doses are omeprazole $120 \mathrm{mg}$, rifabutin $150 \mathrm{mg}$, and amoxicillin $3 \mathrm{~g}$. This should provide a more simplified treatment regimen comprising 12 identical capsules of a single combination product rather than multiple medicines in variable doses. Myelotoxicity, which is a rare complication of treatment with rifabutin, is largely confined to doses greater than $600 \mathrm{mg}$ per day, and/or to prolonged use [54]. As such, this should not be an issue with Talicia ${ }^{\circledR}$ given that the total rifabutin dose would be $150 \mathrm{mg}$ daily for 14 days. Furthermore, the development of narrow-spectrum agents against $H$. pylori-specific targets remains an area of active research and provides ample opportunity since numerous $H$. pylori genomes, with potentially novel targets for drug development, have been sequenced $[23,60]$. The development of newer, more effective treatments for $H$. pylori infection has not been a major focus of the pharmaceutical industry in recent years. This reflects the fact that the infection is most prevalent in poorer, less developed nations and that effective treatment would-necessarily-be of short duration and prescribed only once without opportunities for repeat prescriptions or more prolonged use [61]. However, with the emergence of these simpler approaches, this may finally be changing.

\section{Acid suppression with potassium-competitive acid blockers}

Vonoprazan, the first-in-class and most extensively studied potassium-competitive acid blocker (P-CAB), has a more rapid onset of action, longer duration, and more profound acid suppression than PPIs [62]. In clinical trials in Japan, investigators have substituted it for a PPI. This, in general, has resulted in $10-20 \%$ higher eradication rates when used in clarithromycin-based 
Table 2. Treatment of Helicobacter pylori patients with prior failed attempts. Based on Recommendations from the American College of Gastroenterology (ACG), Toronto Consensus and Maastricht V/Florence Report. Reproduced with permission from Fallone et al. [23]

\begin{tabular}{|c|c|c|c|}
\hline Regimen & ACG & Toronto $^{a}$ & Maastricht V/Florence \\
\hline $\begin{array}{l}\text { Bismuth quadruple } \\
\text { therapy }\end{array}$ & Recommended choice & $\begin{array}{l}\text { Recommended } \\
\text { choice }\end{array}$ & Recommended choice \\
\hline Levofloxacin therapy ${ }^{b}$ & Recommended choice & $\begin{array}{l}\text { Recommended } \\
\text { choice }\end{array}$ & Recommended choice \\
\hline $\begin{array}{l}\text { Clarithromycin-based } \\
\text { PPI triple therapy }\end{array}$ & Not Recommended & Not Recommended & $\begin{array}{l}\text { Recommended if failed bismuth quadruple and } \\
\text { levofloxacin and from a low } \\
\text { clarithromycin-resistance area }\end{array}$ \\
\hline $\begin{array}{l}\text { Concomitant } \\
\text { non-bismuth qua- } \\
\text { druple therapy }\end{array}$ & $\begin{array}{l}\text { Recommended if } \\
\text { previous bismuth } \\
\text { quadruple treatment } \\
\text { failed }\end{array}$ & $\begin{array}{l}\text { Not enough evidence } \\
\text { to comment }\end{array}$ & $\begin{array}{l}\text { Recommended if failed bismuth quadruple and } \\
\text { levofloxacin and from a low } \\
\text { clarithromycin-resistance area }\end{array}$ \\
\hline $\begin{array}{l}\text { High-dose dual } \\
\text { therapy }\end{array}$ & Suggested & $\begin{array}{l}\text { Promising but } \\
\text { insufficient } \\
\text { evidence to } \\
\text { recommend }\end{array}$ & $\begin{array}{l}\text { Consider if high rate of dual clarithromycin/ } \\
\text { metronidazole resistance }\end{array}$ \\
\hline Rifabutin therapy & Suggested & $\begin{array}{l}\text { Restricted to those } \\
\text { who failed } \\
\text { treatment } 3 \text { or } \\
\text { more times }\end{array}$ & $\begin{array}{l}\text { Consider if failed clarithromycin based and } \\
\text { bismuth quadruple therapies and is from high } \\
\text { fluoroquinolone resistance area (ie, failed } \\
\text { treatment } 2 \text { or more times) }\end{array}$ \\
\hline
\end{tabular}

triple therapy [63•]. Dual therapy with vonoprazan and amoxicillin has also yielded promising results. Furuta et al reported a $92.9 \%$ eradication rate with vonoprazan $20 \mathrm{mg}$ bid and amoxicillin $500 \mathrm{mg}$ tid, compared with $91.9 \%$ with vonoprazan $20 \mathrm{mg}$ bid, clarithromycin $200 \mathrm{mg}$ bid, and amoxicillin $750 \mathrm{mg}$ bid, with both regimens given for 7 days [64]. Similarly, in a multicenter randomized trial, Suzuki et al. reported eradication rates with dual (vonoprazan $20 \mathrm{mg}+$ amoxicillin $750 \mathrm{mg}$ bid) and triple (vonoprazan $20 \mathrm{mg}+$ amoxicillin $750 \mathrm{mg}$ + clarithromycin $200 \mathrm{mg}$ bid) regimens of $84.5 \%$ and $89.2 \%$, respectively [65]. The more potent and sustained degree of acid suppression with vonoprazan enhances the effectiveness of amoxicillin and could obviate the need for clarithromycin $[23,66]$. A phase 3 clinical trial of vonoprazan-based dual and triple regimens for $H$. pylori infection was underway in the USA and Europe. However, at the time of writing (March 2020), this was temporarily halted in view of the Covid-19 pandemic although has subsequently been resumed. Other P-CABs are currently available in some Asian countries although not used routinely in $H$. pylori eradication regimens [67]. There are subtle differences within the P-CAB class with respect to pharmacodynamics [68], just as have been demonstrated for the PPIs.

\section{Role of probiotics in $\boldsymbol{H}$. pylori management}

Meta-analyses of trials of probiotics containing single or multiple microbial strains have provided little evidence of benefit in improving $H$. pylori eradication rates. Included trials were generally of low quality and had a high risk of bias due to lack of blinding and the use of poorly defined combinations and concentrations of probiotic strains [69, 70]. Despite these limitations, some multi-strain probiotics may improve eradication rates $[62,63]$, and may help to reduce side effects and thus improve compliance with treatment $[69,70]$. Probiotics may offer significant potential in this regard; however, further study is needed to elucidate their influence on ongoing $H$. pylori eradication efforts. 


\section{Development of an $\boldsymbol{H}$. pylori vaccine}

The development of an effective $H$. pylori vaccine that will circumvent the current problem of declining eradiation rates and rising antibiotic resistance would be an attractive management strategy. Although efforts to develop such a vaccine have had little success over the past three decades [23, 71], a recent large phase 3 trial conducted in China using an oral vaccine containing recombinant urease B provided $>70 \%$ protection against natural $H$. pylori infection [72]. This landmark study has renewed interest in the development of a safe and effective $H$. pylori vaccine as a much-needed prophylactic alternative to the use of complex antibiotic regimens for the treatment of established infection.

\section{Conclusions}

Declining H. pylori eradication due to rising antibiotic resistance worldwide is a significant global public health challenge. H. pylori infection is a potentially modifiable risk factor for gastric cancer. H. pylori infection is also still the single most common cause of PUD that, in turn, is the single most common cause of upper gastrointestinal bleeding. The most recent US treatment guideline indicates that a 14-day course of BQT would be the most reliable, empiric first-line therapy. However, this carries many limitations including its complexity and the frequent lack of availability of generic tetracycline. Concomitant non-bismuth quadruple therapy is an alternative. However, in the absence of antibiotic sensitivity testing, this necessarily leads to inappropriate use of individual antibiotics (i.e., clarithromycin or metronidazole) to which the H. pylori strain may already be resistant and the unnecessary addition of metronidazole in the treatment of clarithromycin-sensitive strains. This represents poor antibiotic stewardship. The recent approval of the combination regimen of omeprazole, rifabutin, and amoxicillin is likely to have a major impact on management. Although rifabutin-based regimens were not recommended for first-line use in the 2017 ACG guideline, that document was prepared before the availability of the results of the US-based clinical trial [59].

Antibiotic resistance testing - where available-should still be considered after failure of eradication with two different regimens. All patients should receive posttreatment testing to confirm eradication using the UBT, fecal antigen test, or histology (if endoscopy is performed for another indication) after discontinuing bismuth and antibiotics for 4 weeks, and PPIs for at least 2 weeks. The potential incorporation of vonoprazan or other P-CABs into eradication regimens is of great interest. Studies from Japan and other Asian countries have yielded promising results. Now that the phase 3 trial in the USA and Europe has been resumed, its results will be of great interest.

As pre-treatment susceptibility testing (including molecular and stool-based testing) is unlikely to be widely available any time soon, coordinated efforts to obtain local and regional resistance and susceptibility data will form the basis of effective management while attempting to uphold principles of antibiotic stewardship. In the absence of resistance testing by traditional or molecular methods, empiric H. pylori eradication therapy should be based, whenever possible, on regional or population-specific antibiotic susceptibility data as well as knowledge of individual patients' personal antibiotic histories and the presence of true penicillin allergy. 
The emergence of simpler 14-day regimens and combination products should improve practice and simplify current cumbersome treatment regimens. Such efforts to improve patient compliance should lead to higher eradication rates. In the meantime, effective management comprises appropriate diagnostic testing, avoidance of ineffective regimens, and routine post-treatment confirmation of eradication.

\section{Compliance with ethical standards}

\section{Conflict of interest}

Dr. Saleem declares that he has no conflict of interest.

Dr. Howden is a consultant for Phathom and for RedHill Biopharma and is a member of the speaker bureau for RedHill Biopharma.

\section{References and Recommended Reading}

1. Hooi JKY, Lai WY, Ng WK, Suen MMY, Underwood FE, Tanyingoh D, et al. Global prevalence of helicobacter pylori infection: systematic review and meta-analysis. Gastroenterology. 2017;153(2):420-9. https://doi. org/10.1053/j.gastro.2017.04.022.

2. Eusebi LH, Zagari RM, Bazzoli F. Epidemiology of helicobacter pylori infection. Helicobacter. 2014;19(Suppl 1):1-5. https://doi.org/10.1111/hel. 12165.

3.• Chey WD, Leontiadis GI, Howden CW, Moss SF. ACG clinical guideline: treatment of Helicobacter pylori infection. Am J Gastroenterol. 2017;112(2):212-39. https://doi.org/10.1038/ajg.2016.563

The most recent treatment guideline for US practice.

4. Nguyen T, Ramsey D, Graham D, Shaib Y, Shiota S, Velez M, et al. The prevalence of helicobacter pylori remains high in African American and Hispanic veterans. Helicobacter. 2015;20(4):305-15. https://doi. org/10.1111/hel.12199.

5. Everhart JE, Kruszon-Moran D, Perez-Perez GI, Tralka TS, McQuillan G. Seroprevalence and ethnic differences in helicobacter pylori infection among adults in the United States. J Infect Dis. 2000;181(4):1359-63. https://doi.org/10.1086/315384.

6. Epplein M, Cohen SS, Sonderman JS, Zheng W, Williams SM, Blot WJ, et al. Neighborhood socioeconomic characteristics, African ancestry, and Helicobacter pylori sero-prevalence. Cancer Causes Control. 2012;23(6):897-906. https://doi.org/10. 1007/s10552-012-9960-7.

7. Grad YH, Lipsitch M, Aiello AE. Secular trends in helicobacter pylori seroprevalence in adults in the United States: evidence for sustained race/ethnic disparities. Am J Epidemiol. 2012;175(1):54-9. https://doi.org/10.1093/aje/kwr288.

8. Dong E, Duan L, Wu BU. Racial and ethnic minorities at increased risk for gastric cancer in a regional US population study. Clin Gastroenterol Hepatol. 2017;15(4):511-7. https://doi.org/10.1016/j.cgh. 2016.11.033.

9. Fallone CA, Chiba N, van Zanten SV, Fischbach L, Gisbert JP, Hunt RH, et al. The Toronto consensus for the treatment of Helicobacter pylori infection in adults. Gastroenterology. 2016;151(1):51-69 e14. https://doi.org/10.1053/j.gastro.2016.04.006.

10. Sugano K, Tack J, Kuipers EJ, Graham DY, El-Omar EM, Miura S, et al. Kyoto global consensus report on Helicobacter pylori gastritis. Gut. 2015;64(9):135367. https://doi.org/10.1136/gutjnl-2015-309252.

11. Wang AY, Peura DA. The prevalence and incidence of Helicobacter pylori-associated peptic ulcer disease and upper gastrointestinal bleeding throughout the world. Gastrointest Endosc Clin N Am. 2011;21(4):613-35. https://doi.org/10.1016/j.giec.2011.07.011.

12. Malfertheiner P, Megraud F, O'Morain CA, Gisbert JP, Kuipers EJ, Axon AT, et al. Management of Helicobacter pylori infection-the Maastricht $\mathrm{V}$ /florence consensus report. Gut. 2017;66(1):6-30. https://doi.org/10. 1136/gutjnl-2016-312288

The most recent European guideline and recommendations related to $H$. pylori infection.

13. Hunt R, Fallone C, Veldhuyzan van Zanten S, Sherman P, Smaill F, Flook N, et al. Canadian Helicobacter study group consensus conference: update on the management of Helicobacter pylori-an evidence-based evaluation of six topics relevant to clinical outcomes in patients evaluated for $\mathrm{H}$ pylori infection. Can J 
Gastroenterol. 2004;18(9):547-54. https://doi.org/10. $1155 / 2004 / 326767$.

14.•• Ford AC, Yuan Y, Moayyedi P. Helicobacter pylori eradication therapy to prevent gastric cancer: systematic review and meta-analysis. Gut 2020; in press Recently updated systeamtic review and meta-analysis of trials showing a reduced risk of gastric cancer through treatment of $H$. pylori infection in asymptomatic individuals and also confirming the benefit of eradication of $H$. pylori infection in patients following endoscopic resection of early gastric neoplastic lesions.

15. Moayyedi P, Lacy BE, Andrews CN, Enns RA, Howden CW, Vakil N. ACG and CAG clinical guideline: management of dyspepsia. Am J Gastroenterol

2017;112(7):988-1013. https://doi.org/10.1038/ajg 2017.154

US/Canadian joint guideline on the management of dyspepsia including discussion of role of testing for and treating H. pylori infection in uninvestigated dyspepsia and functional dyspepsia.

16. Chiba N, Van Zanten SJ, Sinclair P, Ferguson RA, Escobedo S, Grace E. Treating Helicobacter pylori infection in primary care patients with uninvestigated dyspepsia: the Canadian adult dyspepsia empiric treatment-helicobacter pylori positive (CADET-Hp) randomised controlled trial. BMJ.

2002;324(7344):1012-6. https://doi.org/10.1136/ bmj.324.7344.1012.

17. Savoldi A, Carrara E, Graham DY, Conti M, Tacconelli E. Prevalence of antibiotic resistance in Helicobacter pylori: a systematic review and meta-analysis in World Health Organization regions. Gastroenterology. 2018;155(5):1372-82 e17. https://doi.org/10.1053/j. gastro.2018.07.007

Some of the most recent data on antimicrobial resistance rates amongH. pylori strains geographically.

18. Lahaie RG, Gaudreau C. Helicobacter pylori antibiotic resistance: trends over time. Can J Gastroenterol. 2000;14(10):895-9. https://doi.org/10.1155/2000/ 218256.

19. Saad RJ, Chey WD. Persistent Helicobacter pylori infection after a course of antimicrobial therapy-what's next? Clin Gastroenterol Hepatol. 2008;6(10):108690. https://doi.org/10.1016/j.cgh.2008.05.009.

20. Megraud F, Coenen S, Versporten A, Kist M, Lopez-Brea M, Hirschl AM, et al. Helicobacter pylori resistance to antibiotics in Europe and its relationship to antibiotic consumption. Gut. 2013;62(1):34-42. https://doi.org/ 10.1136/gutjnl-2012-302254.

21. McMahon BJ, Hennessy TW, Bensler JM, Bruden DL, Parkinson AJ, Morris JM, et al. The relationship among previous antimicrobial use, antimicrobial resistance, and treatment outcomes for helicobacter pylori infections. Ann Intern Med. 2003;139(6):463-9. https:// doi.org/10.7326/0003-4819-139-6-20030916000008.

22.• Tacconelli E, Carrara E, Savoldi A, Harbarth S, Mendelson M, Monnet DL, et al. Discovery, research, and development of new antibiotics: the WHO priority list of antibiotic-resistant bacteria and tuberculosis. Lancet Infect Dis. 2018;18(3):318-27. https://doi.org/ 10.1016/S1473-3099(17)30753-3

The WHO's position on priorities for development of newer agents for resistant bacterial infections including $H$. pylori.

23. Fallone CA, Moss SF, Malfertheiner P. Reconciliation of recent Helicobacter pylori treatment guidelines in a time of increasing resistance to antibiotics. Gastroenterology. 2019;157(1):44-53. https://doi.org/10. 1053/j.gastro.2019.04.011.

24. Nishizawa T, Suzuki H. Mechanisms of Helicobacter pylori antibiotic resistance and molecular testing. Front Mol Biosci. 2014;1:19. https://doi.org/10.3389/fmolb. 2014.00019.

25. Plummer M, Franceschi S, Vignat J, Forman D, de Martel C. Global burden of gastric cancer attributable to Helicobacter pylori. Int J Cancer. 2015;136(2):48790. https://doi.org/10.1002/ijc.28999.

26. de Martel C, Georges D, Bray F, Ferlay J, Clifford GM. Global burden of cancer attributable to infections in 2018: a worldwide incidence analysis. Lancet Glob Health. 2019. https://doi.org/10.1016/S2214109X(19)30488-7

Interesting perspective that $H$. pylori is responsible for more cancers worldwide than HPV, HBV, or HCV.

27.• Siegel RL, Miller KD, Jemal A. Cancer statistics, 2020. CA Cancer J Clin. 2020;70(1):7-30. https://doi.org/10. 3322/caac. 21590

Official estimates from American Cancer Society about new diagnoses of, and deaths from, various cancers in the USA for 2020; more new cases of gastric cancer than both types of esophageal cancer combined are predicted for 2020.

28.• Kumar S, Metz DC, Ellenberg S, Kaplan DE, Goldberg DS. Risk factors and incidence of gastric cancer after detection of Helicobacter pylori infection: a large cohort studyGastroenterology. 2019. https://doi.org/10. 1053/j.gastro.2019.10.019

Evidence from a US-based study that eradication of $H$. pylori in asymptomatic adults reduces lifetime risk of gastric cancer.

29. Lee YC, Chiang TH, Chou CK, Tu YK, Liao WC, Wu MS, et al. Association between Helicobacter pylori eradication and gastric CANCER incidence: a systematic review and meta-analysis. Gastroenterology. 2016;150(5):1113-24 e5. https://doi.org/10.1053/j.gastro.2016.01.028.

$30 . \bullet$ Choi IJ, Kim CG, Lee JY, Kim YI, Kook MC, Park B, et al. Family history of gastric cancer and Helicobacter pylori treatment. N Engl J Med. 2020;382(5):427-36. https:// doi.org/10.1056/NEJMoa1909666

Important study from South Korea demonstrating that infected first-degree relatives of gastric cancer patients benefit from treatment for $H$. pylori infection.

31. El-Serag HB, Kao JY, Kanwal F, Gilger M, LoVecchio F, Moss SF, et al. Houston consensus conference on testing for Helicobacter pylori infection in the United States. Clin Gastroenterol Hepatol. 2018;16(7):992-1002 e6. https://doi.org/10.1016/j.cgh.2018.03.013

32. Lee YC, Chiang TH, Liou JM, Chen HH, Wu MS, Graham DY. Mass eradication of Helicobacter pylorito 
prevent gastric cancer: theoretical and practical considerations. Gut Liver. 2016;10(1):12-26. https://doi.org/ $10.5009 /$ gnl15091.

33. Asaka M, Mabe K, Matsushima R, Tsuda M. Helicobacter pylori eradication to eliminate gastric cancer: the Japanese strategy. Gastroenterol Clin N Am. 2015;44(3):639-48. https://doi.org/10.1016/j.gtc. 2015.05.010.

34.• Gupta S, Li D, El Serag HB, Davitkov P, Altayar O, Sultan $\mathrm{S}$, et al. AGA clinical practice guidelines on management of gastric intestinal metaplasia. Gastroenterology. 2019. https://doi.org/10.1053/j.gastro. 2019.12.003

American Gastroenterological Association's recommendations for management of gastric intestinal metaplasia.

35. Neunert C, Terrell DR, Arnold DM, Buchanan G, Cines DB, Cooper N, et al. American Society of Hematology 2019 guidelines for immune thrombocytopenia. Blood Adv. 2019;3(23):3829-66. https://doi.org/10. 1182/bloodadvances.2019000966.

36. Siddique O, Ovalle A, Siddique AS, Moss SF. Helicobacter pylori infection: an update for the internist in the age of increasing global antibiotic resistance. Am J Med. 2018;131(5):473-9. https://doi.org/10. 1016/j.amjmed.2017.12.024.

37. Howden CW, Blume SW, de Lissovoy G. Practice patterns for managing Helicobacter pylori infection and upper gastrointestinal symptoms. Am J Manag Care. 2007;13(1):37-44.

38. Theel ES, Johnson RD, Plumhoff E, Hanson CA. Use of the Optum Labs Data Warehouse to assess test ordering patterns for diagnosis of Helicobacter pylori infection in the United States. J Clin Microbiol. 2015;53(4):1358-60. https://doi.org/10.1128/JCM. 03464-14.

39. Dixon MF, Genta RM, Yardley JH, Correa P. Classification and grading of gastritis. The updated Sydney system. International workshop on the histopathology of gastritis, Houston 1994. Am J Surg Pathol. 1996;20(10):1161-81. https://doi.org/10.1097/ 00000478-199610000-00001.

40. Uotani T, Graham DY. Diagnosis of Helicobacter pylori using the rapid urease test. Ann Transl Med. 2015;3(1):9. https://doi.org/10.3978/j.issn.23055839.2014.12.04

41. Choi YJ, Kim N, Lim J, Jo SY, Shin CM, Lee HS, et al. Accuracy of diagnostic tests for Helicobacter pylori in patients with peptic ulcer bleeding. Helicobacter. 2012;17(2):77-85. https://doi.org/10.1111/j.15235378.2011.00915.x.

42. Megraud F, Lehours P. Helicobacter pylori detection and antimicrobial susceptibility testing. Clin Microbiol Rev. 2007;20(2):280-322. https://doi.org/10.1128/ CMR.00033-06.

43. Wenzhen Y, Yumin L, Quanlin G, Kehu Y, Lei J, Donghai $\mathrm{W}$, et al. Is antimicrobial susceptibility testing necessary before first-line treatment for Helicobacter pylori infection? Meta-analysis of randomized controlled trials. Intern Med. 2010;49(12):1103-9. https://doi.org/10.2169/internalmedicine.49.3031.

44. Lopez-Gongora S, Puig I, Calvet X, Villoria A, Baylina M, Munoz N, et al. Systematic review and meta-analysis: susceptibility-guided versus empirical antibiotic treatment for Helicobacter pylori infection. J Antimicrob Chemother. 2015;70(9):2447-55. https:// doi.org/10.1093/jac/dkv155.

45. Shiota S, Reddy R, Alsarraj A, El-Serag HB, Graham DY. Antibiotic resistance of Helicobacter pylori among male United States Veterans. Clin Gastroenterol Hepatol. 2015;13(9):1616-24. https://doi.org/10. 1016/j.cgh.2015.02.005.

46. Duck WM, Sobel J, Pruckler JM, Song Q, Swerdlow D, Friedman $\mathrm{C}$, et al. Antimicrobial resistance incidence and risk factors among Helicobacter pylori-infected persons, United States. Emerg Infect Dis.

2004;10(6):1088-94. https://doi.org/10.3201/ eid1006.030744.

47. Bordin DS, Yanova OB, Abdulkhakov RA, Tsukanov VV, Livzan MA, Burkov SG, et al. European Registry on the management of Helicobacter pylori infection (HpEuReg protocol): the first results of Russian centers. Ter Arkh. 2016;88(2):33-8. https://doi.org/10.17116/ terarkh201688233-38.

48. Beckman E, Saracino I, Fiorini G, Clark C, Slepnev V, Patel D, et al. A novel stool PCR test for Helicobacter pylori may predict clarithromycin resistance and eradication of infection at a high rate. J Clin Microbiol. 2017;55(8):2400-5. https://doi.org/10.1128/JCM. 00506-17.

49. Iannone A, Giorgio F, Russo F, Riezzo G, Girardi B, Pricci $M$, et al. New fecal test for non-invasive Helicobacter pylori detection: a diagnostic accuracy study. World J Gastroenterol. 2018;24(27):3021-9. https://doi.org/10.3748/wjg.v24.i27.3021.

50. Alsamman MA, Vecchio EC, Shawwa K, Acosta-Gonzales G, Resnick MB, Moss SF. Retrospective analysis confirms tetracycline quadruple as best Helicobacter pylori regimen in the USA. Dig Dis Sci. 2019;64(10):2893-8. https://doi.org/10.1007/ s10620-019-05694-4

The most recent "real world" data from the USA about the performance of some widely prescribed combination regimens for $H$. pylori infection.

51. McNicholl AG, Bordin DS, Lucendo A, Fadeenko G, Fernandez MC, Voynovan I, et al. Combination of bismuth and standard triple therapy eradicates Helicobacter pylori infection in more than $90 \%$ of patients. Clin Gastroenterol Hepatol. 2020;18(1):8998. https://doi.org/10.1016/j.cgh.2019.03.048 Evidence that the simple addition of bismuth to a combination regimen may boost eradication rates.

52. Castells M, Khan DA, Phillips EJ. Penicillin allergy. N Engl J Med. 2019;381(24):2338-51. https://doi.org/ 10.1056/NEJMra1807761

Important and authoritative review of the problem of penicillin allergy with reliable estimates of its true prevalence. 
53. Yang JC, Lin CJ, Wang HL, Chen JD, Kao JY, Shun CT, et al. High-dose dual therapy is superior to standard firstline or rescue therapy for Helicobacter pylori infection. Clin Gastroenterol Hepatol. 2015;13(5):895-905 e5. https://doi.org/10.1016/j.cgh.2014.10.036.

54. Gisbert JP, Calvet X. Review article: rifabutin in the treatment of refractory Helicobacter pylori infection. Aliment Pharmacol Ther. 2012;35(2):209-21. https:// doi.org/10.1111/j.1365-2036.2011.04937.x.

55. Chen Q, Long X, Ji Y, Liang X, Li D, Gao H, et al. Randomised controlled trial: susceptibility-guided therapy versus empiric bismuth quadruple therapy for first-line Helicobacter pylori treatment. Aliment Pharmacol Ther. 2019;49(11):1385-94. https://doi. org/10.1111/apt.15273.

56. Yang X, Wang JX, Han SX, Gao CP. High dose dual therapy versus bismuth quadruple therapy for Helicobacter pylori eradication treatment: a systematic review and meta-analysis. Medicine (Baltimore). 2019;98(7):e14396. https://doi.org/10.1097/MD. 0000000000014396 .

57. Labenz J. Current role of acid suppressants in helicobacter pylori eradication therapy. Best Pract Res Clin Gastroenterol. 2001;15(3):413-31. https://doi. org/10.1053/bega.2001.0188.

58. Miehlke S, Kirsch C, Schneider-Brachert W, Haferland C, Neumeyer M, Bastlein E, et al. A prospective, randomized study of quadruple therapy and high-dose dual therapy for treatment of Helicobacter pylori resistant to both metronidazole and clarithromycin. Helicobacter. 2003;8(4):310-9. https://doi.org/10. 1046/j.1523-5378.2003.00158.x.

59•. Graham DY, Canaan Y, Maher J, et al. Rifabutin-based triple therapy (RHB-105) for Helicobacter pylori eradication: A double-blind, randomized, controlled trial. Ann Intern Med 2020;172:795-802.

Publication of the randomized controlled trial of the rifabutinamoxicillin-omeprazole combination product that was approved by the FDA in late 2019.

60. Pasala C, Chilamakuri CSR, Katari SK, Nalamolu RM, Bitla AR, Umamaheswari A. An in silico study: novel targets for potential drug and vaccine design against drug resistant H. pylori. Microb Pathog. 2018;122:156-61. https://doi.org/10.1016/j.micpath. 2018.05.037.

61. Nelson R. Antibiotic development pipeline runs dry. New drugs to fight resistant organisms are not being developed, experts say. Lancet. 2003;362(9397):17267. https://doi.org/10.1016/s0140-6736(03)14885-4.

62. Ohkuma K, Iida H, Inoh Y, Kanoshima K, Ohkubo H, Nonaka T, et al. Comparison of the early effects of vonoprazan, lansoprazole and famotidine on intragastric pH: a three-way crossover study. J Clin Biochem Nutr. 2018;63(1):80-3. https://doi.org/10. 3164/jcbn.17-128.

63. Jung YS, Kim EH, Park CH. Systematic review with meta-analysis: the efficacy of vonoprazan-based triple therapy on Helicobacter pylori eradication. Aliment Pharmacol Ther. 2017;46(2):106-14. https://doi.org/ 10.1111/apt.14130

Evidence from Asian studies of the efficacy of the P-CAB vonoprazan as part of combination regimens against $H$. pylori. 64. Furuta T, Yamade M, Kagami T, Uotani T, Suzuki T, Higuchi T, Tani S, Hamaya Y, Iwaizumi M, Miyajima H, Umemura K, Osawa S, Sugimoto K Dual therapy with vonoprazan and amoxicillin is as effective as triple therapy with vonoprazan, amoxicillin and clarithromycin for eradication of Helicobacter pylori. Digestion. 2019:1-9. doi:https://doi.org/10.1159/ 000502287.

65. Suzuki S, Gotoda T, Kusano C, Ikehara H, Ichijima R, Ohyauchi $\mathrm{M}$, et al. Seven-day vonoprazan and lowdose amoxicillin dual therapy as first-line Helicobacter pylori treatment: a multicentre randomised trial in Japan. Gut. 2020;69:1019-26. https://doi.org/10. 1136/gutjnl-2019-319954.

66. Graham DY, Dore MP. Update on the use of vonoprazan: a competitive acid blocker. Gastroenterology. 2018;154(3):462-6. https://doi.org/10.1053/j. gastro.2018.01.018.

67. Scarpignato C, Hunt RH. Editorial: potassiumcompetitive acid blockers for acid-related diseasestegoprazan, a new kid on the block. Aliment Pharmacol Ther. 2019;50(8):960-2. https://doi.org/ 10.1111/apt.15480.

68. Graham DY, Tansel A. Interchangeable use of proton pump inhibitors based on relative potency. Clin Gastroenterol Hepatol. 2018;16(6):800-8 e7. https://doi.org/10.1016/j.cgh.2017.09.033.

69. McFarland LV, Huang Y, Wang L, Malfertheiner P. Systematic review and meta-analysis: multi-strain probiotics as adjunct therapy for Helicobacter pylori eradication and prevention of adverse events. United Eur Gastroenterol J. 2016;4(4):546-61. https://doi. org/10.1177/2050640615617358.

70. Wang ZH, Gao QY, Fang JY. Meta-analysis of the efficacy and safety of lactobacillus-containing and bifidobacterium-containing probiotic compound preparation in Helicobacter pylori eradication therapy. J Clin Gastroenterol. 2013;47(1):25-32. https://doi. org/10.1097/MCG.0b013e318266f6cf.

71. Zhang S, Moise L, Moss SF. H. pylori vaccines: why we still don't have any. Hum Vaccin. 2011;7(11):1153-7. https://doi.org/10.4161/hv.7.11.17655.

72. Zeng M, Mao XH, Li JX, Tong WD, Wang B, Zhang YJ, et al. Efficacy, safety, and immunogenicity of an oral recombinant Helicobacter pylori vaccine in children in China: a randomised, double-blind, placebo-controlled, phase 3 trial. Lancet. 2015;386(10002):145764. https://doi.org/10.1016/S0140-6736(15)60310-5.

\section{Publisher's Note}

Springer Nature remains neutral with regard to jurisdictional claims in published maps and institutional affiliations. 